\title{
Impact of Proximate Determinants on Fertility Transition Behind the Socio-demographic Factors in Bangladesh: A Hierarchical Approach from the National Survey
}

\author{
Iqramul Haq ${ }^{1 *}$, Sheikh Giash Uddin², Injamul Haq Methun ${ }^{3}$, Aminul Islam $^{4}$, Sultana Bethe ${ }^{2}$, Abdul Latif $^{1}$, \\ Mahabub Alam ${ }^{5}$ \\ 1'Department of Agricultural Statistics, Sher-e-Bangla Agricultural University, Dhaka-1207, Bangladesh \\ ${ }^{2}$ Department of Statistics, Jagannath University, Dhaka -1100, Bangladesh \\ ${ }^{3}$ Statistic Discipline, Tejgaon College, Dhaka-1215, Bangladesh \\ ${ }^{4}$ Office of the Deputy Commissioner, Shariatpur, Bangladesh \\ ${ }^{5}$ Bangladesh Bureau of Statistics (BBS), Statistics and Informatics Division, Ministry of Planning, Dhaka, Bangladesh
}

Corresponding Author: Iqramul Haq, MSc, Lecturer, Department of Agricultural Statistics, Sher-e-Bangla Agricultural University, Dhaka-1207, Bangladesh. Tel: +880-1715331220, Email: iqramul.haq@sau.edu.bd

Received January 26, 2019; Accepted May 3, 2019; Online Published May 29, 2019

\begin{abstract}
Introduction: Fertility is a vital ingredient in measuring population fluctuation. Bangladesh is still above the level of replacement level fertility. The target of this research was to determine the proximate factors on fertility rate reduction in Bangladesh.

Methods: The 2014 Bangladesh Demographic and Health Survey (BDHS) was used as secondary data. The association between fertility and sociodemographic variables was determined by bivariate analysis. Multiple regression analysis in a hierarchical approach was applied to determine the impact of factors on fertility rate reduction.

Results: In the 2014 BDHS, the mean fertility of women aged $15-49$ years was 2.45 , and $76.5 \%$ of women were married at an early age. Hierarchical multiple regression analysis revealed that education has a significant effect on fertility rate. Increasing the education status of women decreased fertility, while other variants of Model I were controlled. Women who accomplish a secondary or higher education are more likely to have fewer children than illiterate women.

Conclusion: The findings of the current study strongly recommend that efforts be made to augment female education, to inform women of the negative impact of early marriage, and to enhance the quality of contraceptive use for all ever-married women, particularly those living in the eastern region. Such steps would be the largest contribution to a future reduction in fertility rates in Bangladesh.

Keywords: Fertility, Socioeconomic, Abortions, Proximate Determinants
\end{abstract}

Citation: Haq I, Uddin SG, Methun IH, et al. Impact of proximate determinants on fertility transition behind the socio-demographic factors in Bangladesh: a hierarchical approach from the national survey. Int J Travel Med Glob Health. 2019;7(2):62-68. doi:10.15171/ijtmgh.2019.14.

\section{Introduction}

A 2017 UN report declared the global total fertility rate (TFR) to be 2.5. ${ }^{1}$ Africa and Europe have the highest and lowest fertility rates, respectively, according to a recent study conducted by the UN. ${ }^{1}$ The study also revealed that $46 \%$ of the world's populations have lower fertility, which is less than the replacement level of fertility (2.10). Another $46 \%$ of the world's population lives in intermediate-fertility countries according to the UN study. ${ }^{1}$

Bangladesh has made salient strides in fertility fluctuations in the last four decades. The TFR has fallen from 6.3 in 1975 to 2.3 in 2014 according to the2014 Bangladesh Demographic and Health Survey (BDHS). ${ }^{2}$ Contraceptive use increased over eight-fold between 1975 and 2014. It was observed that the contraceptive prevalence rate (CPR) and TFR are inversely related to each other If CPR would rise 9.0 percentage points then fertility rate was reduced 0.66 points in this period. ${ }^{2}$

In Oman, fertility decreased when women were modernized, their educational status was improved, and they were engaged in work outside the home. ${ }^{3}$

Fertility fluctuation is a common phenomenon in Bangladesh, where various researchers have shown that decreased fertility is mainly due to successful contraceptive use and have argued that contraception has played a

Copyright $\odot 2019$ The Author(s). This is an open-access article distributed under the terms of the Creative Commons Attribution License (http:// creativecommons.org/licenses/by/4.0), which permits unrestricted use, distribution, and reproduction in any medium, provided the original work is properly cited. 
momentous role in the deterioration of women's fertility rates. ${ }^{4,5}$ In Sub-Saharan Africa, natural methods have played a significant role in fertility regulation. ${ }^{6}$ In the Philippines, fertility differentials depend mainly on effective contraceptive methods and socioeconomic status. ${ }^{7}$ Among all proximate determinants, the controlling effect of fertility for marriage and postpartum fecundability in Ethiopia were highest in 2011 and 2016, respectively. ${ }^{8}$ Research conducted in Asian countries showed that, the fertility rate was decreased despite the diversity of the socio-economic status of population subgroups. ${ }^{9}$ A study of sub-Saharan Africa has shown that the upward trend in urbanization is correlated with fertility transition. ${ }^{10}$ The decline in fertility in sub-Saharan Africa is related to numerous women remaining unmarried and, to a lesser degree, increased contraceptive use. ${ }^{11}$ In a study of 21 sub-Saharan African countries, the researcher ${ }^{12}$ determined that women from rich households have a swifter reduction in fertility rates, greater delay in marrying, and higher contraceptive use compared with women from poor households.

Several researchers have argued that fertility variation occurs because of residence, education, and the economic status of women..$^{11,13-15}$ Fluctuations in fertility are exceedingly and indirectly dependent upon the educational status of women. A researcher ${ }^{16}$ showed that most literate women have a continuously lower fertility rate. The current study aimed to determine the factors contributing to decreasing fertility in Bangladesh. More precisely, those socio-demographic and proximate factors that have dominance on fertility degradation in the context of Bangladesh were examined.

\section{Methods}

Sources of Data

The current study is based on secondary data adopted from the 2014 BDHS. The sample is nationally representative and covers the entire population residing in noninstitutional dwelling units in Bangladesh.

\section{Sampling Techniques}

This cross-sectional survey was conducted on a two-stage stratified sample of households. In the first stage, 600 enumeration areas (EAs), 207 in urban areas and 393 in rural areas, were selected with probability proportional to the EA size. In the second stage of sampling, a systematic sample of 30 households (on average) per EA was selected to provide statistically reliable estimates of key demographic and health areas separately for each of these divisions.

\section{Sample Size}

The survey covered 17989 residential households from the 2014 BDHS. From those sampled households, 17886 ever-married women aged 15-49 years were interviewed, and 17863 women were chosen to participate. ${ }^{2}$ The weight factor applied to this data represents the whole population of Bangladesh, based on the BDHS weighting factors.

\section{Inclusion and Exclusion Criteria}

This survey was conducted on a voluntary basis with ever- married women 15-49 years of age. Those who were usual members of the selected households or who spent the night before the survey in the selected households were eligible for the female survey. Ever-married women under the age of 15 or above the age of 49 were excluded from the survey.

\section{Data Collection}

Data was collected from the 2014 BDHS and three questionnaires: a Household Questionnaire, a Woman's Questionnaire, and a Community Questionnaire. Draft questionnaires were then circulated to other interested groups and were reviewed by the 2014 BDHS Technical Review Committee. The questionnaires were developed in English and then translated into and printed in Bangla, which respondents spoke fluently.

\section{Dependent Variable}

Fertility was determined by children ever born (CEB); CEB was considered as an output variable.

\section{Independent Variables}

The socioeconomic and demographic variables used as independent variables were residence, wealth index, education, working status, religion, decision-making for contraception, mass media exposure, region, religion, gender of head of household, and four major proximate determinants (age at marriage, use of contraception, abortion, and postpartum infecundability). From the selected predictor variables, many of the independent ones were categorical variables.

\section{Statistical Analysis}

For data analysis, descriptive and inferential statistics were applied. Background characteristics were described by applying frequency distribution and descriptive statistics, such as mean and standard deviation. To determine fertility variations, both bivariate and multivariate methods were applied. To analyze the association between a woman's fertility and other independent variables, t-statistics was employed. Hierarchical multiple regression was applied to get the net effect of each independent variable on fertility after regulating the effect of other independent variables in the model. The Statistical Package for Social Science (SPSS v20.0, IBM Corporation, Armonk, New York, NY, USA) software was used in the beginning of the analysis, and $\mathrm{R}$ version 3.6.0 was employed in the final data analysis.

\section{Results}

The percentage allocation and mean fertility of women aged 1549 years among ever-married women by chosen background features are presented in Table 1. Women living in rural areas will bear more children than women in urban areas (2.57). Poor women were significantly more fertile compared to their counterparts. Table 1 also shows that women's education is inversely linked with mean fertility. Women with a secondary or higher education have only half the number of children that illiterate women have. Working women have an average of 0.29 more births than non-working women. Those women who choose to use contraception potentially have a higher 
Table 1. Percentage Distribution and Mean Fertility of Ever-Married Women Age 15-49 years by Selected Socio-demographic Characteristics, Bangladesh 2014

\begin{tabular}{|c|c|c|c|c|c|}
\hline \multirow{2}{*}{ Characteristics } & \multicolumn{2}{|c|}{ Weighted (Sample Women) } & \multicolumn{2}{|c|}{ Children Ever Born } & \multirow{2}{*}{$P$ Value } \\
\hline & No. & $\%$ & Mean & SD & \\
\hline \multicolumn{6}{|l|}{ Residence } \\
\hline Urban & 5047 & 28.3 & 2.15 & 1.53 & \multirow[t]{2}{*}{$<0.001$} \\
\hline Rural & 12816 & 71.7 & 2.57 & 1.78 & \\
\hline \multicolumn{6}{|l|}{ Wealth Index } \\
\hline Poor & 6767 & 37.9 & 2.73 & 1.85 & \multirow{2}{*}{$<0.001$} \\
\hline Non-Poor & 11096 & 62.1 & 2.32 & 1.64 & \\
\hline \multicolumn{6}{|l|}{ Education } \\
\hline No education & 4455 & 24.9 & 3.51 & 1.87 & \multirow{3}{*}{$<0.001$} \\
\hline Primary & 5209 & 29.2 & 2.67 & 1.69 & \\
\hline Secondary+ & 8199 & 45.9 & 1.74 & 1.27 & \\
\hline \multicolumn{6}{|l|}{ Working Status } \\
\hline No & 11947 & 66.9 & 2.36 & 1.73 & \multirow[t]{2}{*}{$<0.001$} \\
\hline Yes & 5912 & 33.1 & 2.65 & 1.70 & \\
\hline \multicolumn{6}{|c|}{ Decision Making for Contraception } \\
\hline Respondent & 1515 & 8.5 & 2.85 & 1.56 & \multirow{2}{*}{$<0.001$} \\
\hline Others & 16348 & 91.5 & 2.15 & 1.74 & \\
\hline \multicolumn{6}{|c|}{ Mass Media Exposure } \\
\hline No Exposure & 6693 & 37.5 & 2.96 & 1.91 & \multirow{2}{*}{$<0.001$} \\
\hline Exposure & 11170 & 62.5 & 2.15 & 1.52 & \\
\hline \multicolumn{6}{|l|}{ Region } \\
\hline Central & 7334 & 41.1 & 2.38 & 1.68 & \multirow[b]{3}{*}{$<0.001$} \\
\hline Eastern & 4533 & 25.4 & 2.78 & 1.99 & \\
\hline Western & 5997 & 33.6 & 2.30 & 1.51 & \\
\hline \multicolumn{6}{|l|}{ Religion } \\
\hline Muslims & 16096 & 90.1 & 2.48 & 1.75 & \multirow[t]{2}{*}{$<0.001$} \\
\hline Non-Muslims & 1767 & 9.9 & 2.26 & 1.46 & \\
\hline \multicolumn{6}{|c|}{ Gender of Household Head } \\
\hline Male & 15854 & 88.8 & 2.46 & 1.74 & \multirow{2}{*}{0.052} \\
\hline Female & 2009 & 11.2 & 2.39 & 1.57 & \\
\hline \multicolumn{6}{|l|}{ Age at Marriage } \\
\hline$<18$ & 13657 & 76.5 & 2.63 & 1.76 & \multirow[t]{2}{*}{$<0.001$} \\
\hline$\geq 18$ & 4206 & 23.5 & 1.88 & 1.48 & \\
\hline \multicolumn{6}{|l|}{ Contraception } \\
\hline Not using & 7336 & 41.1 & 2.30 & 1.94 & $<0.001$ \\
\hline Using & 10527 & 58.9 & 2.56 & 1.55 & \\
\hline Abortion & & & & & \\
\hline No & 14439 & 80.8 & 2.69 & 1.71 & $<0.001$ \\
\hline Yes & 3424 & 19.2 & 2.40 & 1.73 & \\
\hline Postpartum Infec & & & & & \\
\hline Absent & 16774 & 93.9 & 2.47 & 1.75 & $<0.001$ \\
\hline Present & 1089 & 6.1 & 2.26 & 1.37 & \\
\hline
\end{tabular}

number of children than their counterparts. Women who were exposed to mass media (radio/newspaper/TV) had a lower number of children compared with their counterparts. Women who continue having the highest fertility in the eastern region compared with the western region show the lowest fertility values. Muslim women have on average 0.22 more children than their counterparts. Women married before the age of 18 have more children than those who marry later. Women who use contraceptives have significantly higher fertility rates than women who do not use a contraceptive. Women who have had an abortion tend to have lower fertility than women who have not. Women who had a lower duration of postpartum infecundability had fewer children.

\section{Multivariate Analysis}

To get the net effect of each controlled variable on fertility after regulating the consequences of other explanatory variables in the model, the hierarchical multiple regressions approach was applied. The output variable of the study was children ever born (CEB). the independent variables of the study are place of residence, wealth index, educational status, working status, decision to use contraception, mass media exposure (newspaper/radio/TV), region, religion, and four proximate variables (age at first marriage, contraception, abortion, and postpartum infecundability).

A four-step hierarchical multiple regression approach was applied with children born as the dependent variable (Table 2). In Table 2 , all socioeconomic variables and one proximate variable (age at marriage) are entered at Step1 (Model I). The contraception variables are re-added with the interaction between age and use of contraception in Step 2 (Model II). Abortion is entered in Step 3 (Model III). Finally, postpartum infecundability is entered in Step 4 (Model IV).

Hierarchical multiple regression analysis revealed that at Step 1 (Table 2), all socioeconomic and one proximate variable (age at marriage) are significant predictors of fertility 
Table 2. Effect of Selected Socioeconomic Variables and Proximate Factors on Fertility Fluctuation (Multiple Regression Analysis Based on a Hierarchical Method)

\begin{tabular}{|c|c|c|c|c|}
\hline \multirow{2}{*}{ Variable } & Model I & Model II & Model III & Model IV \\
\hline & $\beta$ (SE) & $\beta(\mathrm{SE})$ & $\beta$ (SE) & $\beta$ (SE) \\
\hline \multicolumn{5}{|l|}{ Residence } \\
\hline Urban (ref.) & - & - & - & - \\
\hline Rural & $0.171^{* * *}(0.029)$ & $0.159 * * *(0.026)$ & $0.160 * * *(0.026)$ & $0.159^{* * *}(0.026)$ \\
\hline \multicolumn{5}{|l|}{ Wealth index } \\
\hline Poor (ref.) & - & - & - & - \\
\hline Non-Poor & $0.215^{* * *}(0.034)$ & $0.059 *(0.031)$ & $0.058^{*}(0.031)$ & $0.060 *(0.032)$ \\
\hline \multicolumn{5}{|l|}{ Education } \\
\hline No education (ref.) & - & - & - & - \\
\hline Primary & $-0.790^{* * *}(0.031)$ & $-0.565^{* * *}(0.029)$ & $-0.565^{* * *}(0.029)$ & $-0.569 * * *(0.029)$ \\
\hline Secondary+ & $-1.580 * * *(0.031)$ & $-1.124 * * *(0.030)$ & $-1.125^{* * *}(0.030)$ & $-1.132 * * *(0.030)$ \\
\hline \multicolumn{5}{|l|}{ Working status } \\
\hline No (ref.) & - & - & - & - \\
\hline Yes & $0.134 * * *(0.025)$ & $0.043(0.023)$ & $0.040(0.023)$ & $0.042(0.023)$ \\
\hline Respondent (ref.) & - & - & - & - \\
\hline Others & $-0.309 * * *(0.041)$ & $-0.027(0.039)$ & $-0.030(0.039)$ & $-0.030(0.039)$ \\
\hline \multicolumn{5}{|l|}{ Mass media exposure } \\
\hline No exposure (ref.) & - & - & - & - \\
\hline Exposure & $-0.345^{* * *}(0.030)$ & $-0.313^{* * *}(0.027)$ & $-0.313^{* * *}(0.027)$ & $-0.312^{* * *}(0.027)$ \\
\hline \multicolumn{5}{|l|}{ Region } \\
\hline Central (ref.) & - & - & - & - \\
\hline East & $0.463 * * *(0.029)$ & $0.474^{* * *}(0.027)$ & $0.475^{* * *}(0.027)$ & $0.474^{* * *}(0.027)$ \\
\hline West & $-0.140 * * *(0.027)$ & $-0.195 * * *(0.025)$ & $-0.195^{* * *}(0.025)$ & $-0.191^{* * *}(0.025)$ \\
\hline \multicolumn{5}{|l|}{ Religion } \\
\hline Muslims (ref.) & - & - & - & - \\
\hline Non-Muslims & $-0.155^{* * *}(0.039)$ & $-0.247^{* * *}(0.035)$ & $-0.244 * * *(0.035)$ & $-0.243^{* * *}(0.035)$ \\
\hline \multicolumn{5}{|l|}{ Age at marriage } \\
\hline$<18$ (ref.) & - & - & - & - \\
\hline Not using (ref.) & & - & - & - \\
\hline Using & & $-2.671 * * *(0.057)$ & $-2.653^{* * *}(0.057)$ & $-2.643^{* * *}(0.057)$ \\
\hline \multicolumn{5}{|l|}{ Abortion } \\
\hline No (ref.) & & & - & - \\
\hline Yes & & & $0.089 * *(0.027)$ & $0.091^{* * *}(0.027)$ \\
\hline \multicolumn{5}{|l|}{ Postpartum infecundability } \\
\hline Absent (ref.) & & & & - \\
\hline Present & & & & $0.135^{* *}(0.045)$ \\
\hline \multicolumn{5}{|l|}{ Interaction terms } \\
\hline Age *using contraception & & $0.100^{* * *}(0.002)$ & $0.099 * * *(0.002)$ & $0.100^{* * *}(0.002)$ \\
\hline R-square & 0.219 & 0.351 & 0.351 & 0.352 \\
\hline F-ratio & $417.32^{* * *}$ & $689.31^{* * *}$ & $644.45^{* * *}$ & $605.02^{* * *}$ \\
\hline R-square change & $0.219^{* * *}$ & $0.132^{* * *}$ & $0.000^{* *}$ & $0.000^{* *}$ \\
\hline
\end{tabular}

Note: ref.=reference category and significant at $* * * P<0.001, * * P<0.01$ and $* P<0.05$.

in Bangladesh $(P<0.001)$. As seen in Table 2, the R-squared is 0.219 for the women's age group of 15-49 years, showing that $21.9 \%(P<0.001)$ of the variations in women's CEB in Bangladesh is explained by the independent variables considered in Model I. Place of residence also plays a significant role in fertility.

Women who live in rural areas have more children $(\beta=0.171)$ than those in urban areas, and this factor controls other variables in the Model I. The findings of this study clearly demonstrate that the non-poor women tended to have more children $(\beta=0.215)$ than their poor counterparts. Model I in Table 2 also shows that the highest education level of women is significantly and inversely proportional to fertility at a $1 \%$ significance level. To be more precise, a higher education level among women corresponds to a lower fertility rate, while it also controls other variables in Model I. Women with only a primary school education had lower fertility than uneducated women $(P<0.001)$. Women with secondary and higher education levels had fewer children $(\beta=-1.580)$ than uneducated women. The magnitude of the effect is obvious in the 2014 BDHS, which reported that women with secondary and higher levels of education have, on average, 1.58 fewer children than women with no education. Working women have more children than non-working women.

From Model I in Table 2, it can be observed that women who were engaged with mass media (newspaper, radio, and 
TV) have fewer children ( $\beta=-0.345)$ than their contrast group $(P<0.001)$. Region also affects fertility levels. Respondents from the eastern region had 0.463 more children on average than those in the central region $(P<0.001)$, while women in the western region had 0.140 fewer children on average than those in the central region $(P<0.001)$. Non-Muslim women were likely to have lower fertility $(\beta=-0.155)$ than Muslim women $(P<0.001)$. Women who were older at their first marriage (18 years or above) had fewer children $(\beta=-0.465)$ than their opposite group (at 0.001 significant levels), while other variables in Model I were controlled.

In the second step, contraception, interaction between age and contraception use, in addition to all socioeconomic and age at marriage, were regressed on the dependent variable. Where contraception variables were added in Model II, the explained variance in women's fertility rate increased from $21.9 \%$ in Model I to $35.1 \%$ in Model II. More precisely, introducing the contraception variables explained $13.2 \%$ of the change in fertility levels and significant at a $0.1 \%$ level of significance. Table 2 shows that place of residence also plays a significant role in fertility rates. Women who live in rural areas have more children $(\beta=0.159)$ than those in urban areas. Non-poor women tend to have a greater number of children $(\beta=0.059)$ than poor women. The second model in Table 2 also shows that the highest education level of women significantly affects their fertility rates. Women with a secondary or higher level of education had fewer children $(\beta=-1.124)$ than uneducated women. Model II in Table 2 demonstrates that mass media also has a significant influence on women's fertility rates. Respondents of the eastern region were more likely to have more children on average compared with those in the central Region. Moreover, women in the western region were likely to have fewer children on average than those in the central region $(P<0.001)$. Non-Muslim women had fewer children $(\beta=-0.247)$ than Muslim women $(P<0.001)$. Women who married at an older age had 0.559 fewer children than women who married at a younger age (less than 18 years). Contraception had the highest effect on women's fertility rates among the proximate determinants of fertility. Of the respondents, those women who were using contraception tended to have fewer children $(\beta=-2.671)$ than those women not using a contraceptive. This result suggests that women who used contraception had 2.671 fewer CEB than women who used no contraception at all. The only interaction term found to be statistically significant was the multiplicative term: age $\times$ using contraception.

In Step 3, adding abortion to the regression in Model III expressed an extra $0.0 \%$ variation in fertility rates, and this change in $\mathrm{R}^{2}$ is significant at $P<0.01$. Finally, the addition of postpartum infecundability to the regression model explained an additional $0.1 \%$ of the variation in fertility at a significance level of $P<0.01$. When all four proximate variables were comprised in the final stage (Model IV) of the regression models, all proximate and sociodemographic variables had significant effects on fertility rates except working status and deciding to use contraception. Together, all the sociodemographic and four proximate variables accounted for $35.2 \%$ of the variation in fertility rates.

\section{Discussion}

The current study found that the women have an average of 2.50 births during their reproductive years. Significant differences in fertility under women's place of residence, wealth index, educational status, mass media exposure, age at marriage, use of contraception, abortion, postpartum infecundability, and an interaction term were observed in the current study.

The findings of the current study showed that place of residence also plays an important role in fruitfulness. ${ }^{13}$ The findings also showed that women in rural areas have higher fertility rates than urban women. Researchers ${ }^{4,17,18}$ observed that the rate of fertility in rural areas is still higher than in urban areas of Bangladesh. This outcome is consistent with the study of sub-Saharan Africa and Uganda in some respects, and the fertility rate is lower in urban areas. ${ }^{10,15}$

Women from rich households had more children than poor women. There was no significant effect of wealth index on women's fertility. ${ }^{19}$ This finding is not compatible with those of prior studies. ${ }^{15,18}$ Women who dwell in rich families have approximately twice as few children as those living in proletarian households. ${ }^{7}$ Women residing in proletarian households have higher fertility rates and less contraceptive usage smaller than women from affluent households. ${ }^{20}$

The results of the study suggest that having accomplished a secondary or higher level of education is significantly negatively correlated with CEB. The impact of education on fertility rates is unequivocally huge in the 2014 BDHS, which reported that women who have completed a secondary or higher education level have, on average, 1.50 fewer children than illiterate women. This result is in agreement with prior studies conducted in Bangladesh. ${ }^{18,31}$ Various study audits by researchers ${ }^{15,16,21-23}$ have revealed that having children is negatively correlated with the educational strata of women. Less educated women have more children spaced closely together, in contrast to highly educated women. ${ }^{24}$ The results also show that working women have more children than non-working women. This is analogous to the studied cases in Bangladesh. ${ }^{25}$ The magnitude of women's empowerment in regulating fruitfulness was also alluded to in a prior study conducted in Bangladesh. ${ }^{26}$

The current research hints that access to media has an important and positive influence on reducing fertility rates among women. Women who are involved in mass media (newspaper, radio, and TV) have fewer children in contrast to women who are not exposed to any media. In Bangladesh, fertility rates were decreased among women who were significantly involved in mass media. ${ }^{19}$

Fertility is also affected by regional diversity. Women residing in the eastern region had high fertility rates at the time of this research in contrast with women dwelling in the central region. Women dwelling in the western region had comparatively lower fertility rates than those dwelling in the central region. The study performed in Bangladesh ${ }^{19}$ reported that fruitfulness is not identical in every region of Bangladesh. Non-Muslim women had a lower fertility rate in Bangladesh than Muslim women. In a study in New Zealand, researchers ${ }^{23}$ argued that Christian women had higher fertility rates than 
women of any other religion. A positive relationship between religiosity and matrimonial fruitfulness was reported in a study directed by Muslim women in Israel. ${ }^{27}$

The age at first matrimony is significant and negatively influences women's fertility. The present study unequivocally suggests that women who are married at age 18 years or older have fewer children than women who are married at a very young age (under 18 years of age). This result is in agreement with findings of several studies conducted in Bangladesh, which observed that later matrimony played a significant role in reproduction reduction. ${ }^{17}$ In a study of Ethiopian women in both urban and rural areas, the researcher ${ }^{28}$ showed that it took many people married at an early age to trigger a rise in the probability that women will have more children in their reproductive years. Among the proximate determinants of fertility, marriage had the highest controlling effect on fertility in studies of Ethiopia, ${ }^{8}$ Zambia, ${ }^{14}$ and Namibia. ${ }^{29}$

The current study indicates that, among all the closest determiners of fertility rates, contraceptive use is one of many significant factors which directly influences fertility; women who use contraception are more likely to have fewer children than women who do not use contraceptives during their reproductive years. The findings of the current study expressly identify contraceptive use as the most common reproduction reduction factor in Bangladesh. In a study of urban and rural areas of Bangladesh, researchers ${ }^{4}$ observed that the effectiveness of contraceptive use is the most important factor for reducing fertility in both areas. In Bangladesh, a subsequent decrease in fertility rate can basically depend on the increased use of effective birth control methods. ${ }^{30}$ Researchers ${ }^{13}$ have shown that the use of effective birth control methods is an original reason for reduced fertility rates in Bangladesh. This current research is similar to a previous study conducted in 21 sub-Saharan African countries based on the economic status of women. ${ }^{12}$ Another interesting outcome of the research showed that women who experience an abortion during their reproductive years have a higher fertility rate than women who do not. This is contrary to the results of various previous studies conducted in Bangladesh. ${ }^{18,30}$ Reduced reproduction across Asian countries is accompanied by the maximum spread of contraceptive use followed by age at marriage pattern and induced abortion. ${ }^{9}$

\section{Conclusion}

In the current study, Bangladesh was observed to still have a fertility rate that is higher than the replacement level, and many factors are directly or indirectly related to this phenomenon. Among these factors, age at marriage, education, residence, contraception use, mass media exposure, religion, and abortions are an important determinant of the fertility transition in Bangladesh. Older age at first marriage significantly minimized the TFR of women. Thus, programs should focus on creating wariness of the marriage law and the negative effect of early marriage in the society and country of Bangladesh. Moreover, longrunning programs should focus on increasing the educational strata of women. When women's educational strata increases,

\section{Research Highlights}

What Is Already Known?

The effect of proximate determinants on fertility rate reduction was investigated using mainly Bongaarts Fertility Model. However, several studies have observed that fertility rate reduction is based on socio-demographic factors.

\section{What This Study Adds?}

This study investigated the net effects of proximate determinants on fertility variation in Bangladesh, applied by a hierarchical regression approach. The current study also assessed the association between socio-demographic factors and proximate determinants on fertility rates. The results revealed that women's socio-economic status is not an important factor on fertility variation, and women from the eastern region have the highest fertility in all areas of Bangladesh. Contraception causes a large change in R-squared, which implies that fertility reduction is largely dependent upon contraceptive practices in Bangladesh. Postpartum infecundability has also had a positive effect on fertility in Bangladesh.

age at marriage is significantly increased, and consequently, fertility rates are strongly influenced. Likewise, it is important to emphasize that messages should be expressed through the media regarding small family size and the benefits of family planning. Induced abortion has emerged as an indispensable factor in fertility decline in Bangladesh. Among the four nearest determinants in this study, contraceptive use has made the biggest contribution to the reduction of reproduction in Bangladesh. As a result, it can be concluded that reducing reproduction in Bangladesh depends on the increased use of effective contraceptive methods and achieving the FP2020 goal of enabling $80 \%$ of women and girls to use contraceptives by 2021 , which is critical to meeting sustainable development goals 3 and 5 (SDG 3 and SDG 5).

\section{Authors' Contributions}

SGU had the original idea for this study. All authors contributed to all the experimental work and manuscript writing. IH, IHM and MA contributed extensively to statistical analysis. All authors read and approved the final manuscript.

\section{Conflict of Interest Disclosures}

The authors declare that they have no conflicts of interest.

\section{Funding/Support}

No financial support was received in conducting this study.

\section{Acknowledgments}

The authors would like to express their appreciation to the National Institute of Population Research and Training NIPORT, Bangladesh, and MEASURE DHS for allowing the use of the 2014 Bangladesh Demographic Health Survey 
(BDHS) data in this analysis.

\section{References}

1. United Nations, Department of Economic and Social Affairs, Population Division. World Population Prospects; 2017.

2. National Institute of Population Research and Training (NIPORT), Mitra and Associates, and ICF International. Bangladesh Demographic and Health Survey 2014. Dhaka, Bangladesh, and Rockville, Maryland, USA: NIPORT, Mitra and Associates, and ICF International; 2016.

3. Islam MM. Rapid fertility decline in Oman: Understanding the role of proximate determinants. Middle East Fertil Soc J. 2017;22(4):275-284. doi:10.1016/j.mefs.2017.04.007.

4. Hasan MM, Islam M, Sakib S, Haq I. Influences of Proximate Determinates on Fertility Among Urban and Rural Women in Bangladesh. Dhaka Univ J Sci. 2018;66(1):49-54.

5. Uddin MS, Azad AK, Kibria MG. Factors divide fertility between east and west areas of Bangladesh: implications for further strengthening the family planning program. Bangladesh J Sci Res. 2013;26(1-2):37-46. doi:10.3329/bjsr.v26i1-2.20229.

6. Rossier C, Corker J. Contemporary use of traditional contraception in sub-Saharan Africa. Popul Dev Rev. 2017;43(Suppl 1):192-215. doi:10.1111/padr.12008.

7. Lai SL, Tey NP. Socio-economic and proximate determinants of fertility in the Philippines. World Appl Sci J. 2014;31(10):18281836. doi:10.5829/idosi.wasj.2014.31.10.591.

8. Laelago T, Habtu Y, Yohannes S. Proximate determinants of fertility in Ethiopia; an application of revised Bongaarts model. Reprod Health. 2019;16(1):13. doi:10.1186/s12978-019-0677-x.

9. Majumder N, Ram F. Explaining the role of proximate determinants on fertility decline among poor and non-poor in Asian countries. PLoS One. 2015;10(2):e0115441. doi:10.1371/journal. pone.0115441.

10. Flückiger M, Ludwig M. Urbanization, fertility and child education in Sub-Saharan Africa. Econ Lett. 2017;157:97-102. doi:10.1016/j. econlet.2017.05.024.

11. Madhavan S. An analysis of the proximate determinants of fertility in sub-Saharan Africa with a focus on induced abortion. Baltimore: Johns Hopkins University; 2014.

12. Finlay JE, Mejía-Guevara I, Akachi Y. Inequality in total fertility rates and the proximate determinants of fertility in 21 sub-Saharan African countries. PLoS One. 2018;13(9):e0203344. doi:10.1371/ journal.pone.0203344.

13. Islam R, Islam N, Rahman M, Hossain G, Islam R. Fertility situation in Bangladesh: application of revised Bongaarts model. Sci Technol. 2015;5(2):33-38.

14. Chola M, Michelo C. Proximate determinants of fertility in Zambia: Analysis of the 2007 Zambia Demographic and Health Survey. Int J Popul Res. 2016;2016:5236351. doi:10.1155/2016/5236351.

15. Rutaremwa G, Galande J, Nviiri HL, Akiror E, Jhamba T. The contribution of contraception, marriage and postpartum insusceptibility to fertility levels in Uganda: an application of the aggregate fertility model. Fertil Res Pract. 2015;1:16. doi:10.1186/ s40738-015-0009-y.

16. Eloundou-Enyegue P, Giroux S, Tenikue M. African transitions and fertility inequality: a demographic Kuznets hypothesis. Popul Dev Rev. 2017;43(S1):59-83. doi:10.1111/padr.12034.

17. Haq I. Relationship between age at marriage, education and fertility among residence of Bangladesh. Am J Soc Sci Res. 2018;4(2):33-39.

18. Haq I, Alam M, Methun IH. Contributions of proximate determinants to fertility transition in Bangladesh: an analysis of Bongaarts' fertility model. Int J Travel Med Glob Health. 2019;7(1):23-32. doi:10.15171/ijtmgh.2019.06.

19. Rabbi AM. Factors influencing fertility preference of a developing country during demographic transition: Evidence from Bangladesh. South East Asia J Public Health. 2014;4(2):23-30. doi:10.3329/ seajph.v4i2.23691.

20. Adebowale SA, Adedini SA, Ibisomi LD, Palamuleni ME. Differential effect of wealth quintile on modern contraceptive use and fertility: evidence from Malawian women. BMC Womens Health. 2014;14(1):40. doi:10.1186/1472-6874-14-40.

21. Kim J. Female education and its impact on fertility. IZA World Labor. 2016:228. doi:10.15185/izawol.228.

22. Girma S, Paton D. Is education the best contraception: The case of teenage pregnancy in England? Soc Sci Med. 2015;131:1-9. doi:10.1016/j.socscimed.2015.02.040.

23. Urale PWB, O'Brien MA, Fouché CB. The relationship between ethnicity and fertility in New Zealand. Kōtuitui: New Zealand Journal of Social Sciences Online. 2019;14(1):80-94. doi:10.1080 /1177083X.2018.1534746.

24. Adebowale SA, Palamuleni ME. Childbearing dynamics among married women of reproductive age in Nigeria: re-affirming the role of education. Etude Popul Afr. 2014;27(2):301-318. doi:10.11564/27-2-476.

25. Alam MA, Chamroonsawasdi K, Chansatitporn N, Munsawaengsub C, Islam MS. Regional Variations of Fertility Control Behavior among Rural Reproductive Women in Bangladesh: A Hierarchical Analysis. Behav Sci (Basel). 2018;8(8). doi:10.3390/bs8080068.

26. Rahman MM, Mostofa MG, Hoque MA. Women's household decision-making autonomy and contraceptive behavior among Bangladeshi women. Sex Reprod Healthc. 2014;5(1):9-15. doi:10.1016/j.srhc.2013.12.003.

27. Schellekens J, Atrash A. Religiosity and marital fertility among Muslims in Israel. Demogr Res. 2018;39(34) :911-926. doi:10.4054/DemRes.2018.39.34.

28. Lailulo YA, Sathiya Susuman A. Proximate determinants of fertility in Ethiopia: comparative analysis of the 2005 and 2011 DHS. J Asian AfrStud.2018;53(5):733-748.doi:10.1177/0021909617722373.

29. Palamuleni ME. Determinants of fertility decline in Namibia: an analysis of the proximate determinants. Bangladesh e-J Sociol. Bangladesh e-Journal of Sociology. 2017;14(2):41-63.

30. Haq I. Decomposition of the Change in Proximate Determinants and Its Impacts on Fertility in Bangladesh: An Evidence from National Surveys. Int J Math Comput Sci. 2018;4(1):8-17. 